\title{
NOTES ON A FEW BOMBYCES, HYBRIDS, \&C.
}

\author{
BY ALFRED WAILLY, LONDON, ENGLAND.
}

In my report on silk-producing bombyces and other lepidoptera, reprinted from the Journal of the Society of Arts, $13 \mathrm{Feb}$. and 5 March $1880,{ }^{1} \mathrm{I}$ speak of the disastrous effects of the weather on most species during the year 1879 .

This year, although the splendid weather in August and in the early part of September allowed of the successful rearing of several species in the open air, the wet and cold weather lasting till about the end of July affected and retarded lepidoptera, as in 1879 ; for instance, the moths of Samia promethea had not all emerged before the end of August. With a few exceptions, none of the moths of Indian species emerged at all.

Actias luna. I bred this species this year for the first time, and most successfully, on walnut (Juglans). It thrived well also on a nut tree in my garden, together with larvae of Telea polyphemus and Samia cecropia. Unfortunately the sparrows destroyed all the larvae which were on that tree, when they were already at the end of their third stage. My European correspondents were all, I think, successful with the rearing of Actias luna. Yet I must observe that many ova obtained from well paired A. luna moths and ova of other species, were not fertile, a fact which I attribute to the low temperature of the month of June, affecting the moths.

Samia gloveri. Of this species I received a very large number of cocoons from a young entomologist, but I regret to say the attempt at rearing them was the most complete failure that can be recorded.The moths emerged, from the middle of April to the middle of July, with a few exceptions, all crippled. The greater part of the cocoons did not produce moths ; some were dead on arriving in London; others died later, either from the attacks of parasites or from some other cause. Not a single pairing could be obtained. I would be glad to try this species again.

Samia ceanothi. Of about forty cocoons, the first moth emerged in March, the second on 3 April ; the rest continued to emerge till 18 July. Only two pairings were obtained. The larvae, reared on plum (Prunus) and willow (Salix), did not thrive, and all died, some going into their third stage. None of my correspondents, as far as $I$ know, succeeded with this species. Evidently, plum and willow are not proper food plants for $S$. ceanothi.

The first pairing took place 27 June, the second 10 July. The ova of the first brood hatched 18 days, and those of the second, 15 days, after having been deposited.

The larvae, somewhat similar to those of $S$. cecropia in first and second stage, but of a lighter color, showed a marked difference in the third stage, and were thus: Back of body, sky blue, sides greenish yellow; tubercles golden yellow all along the back, and on the sides, blue; head green.

Hybrids. Although Samia gloveri refused to pair among themselves, I had several crossings between S. gloveri, S. ceanothi, and S. cecropia. The ova obtained

1 Psyche, Rec., no. 1717. 
from a long pairing of $S$. ceanothi $\$$ with $S$. gloveri $\delta$, were the only ones that were fertile. Unfortunately the larvae, reared on willow and plum, all died, some reaching, like $S$. ceanothi, the third stage.

The pairing of S. ceanothi ? with S. gloveri $\hat{\delta}$, was from the evening of 20 to the evening of 21 May. The larvae hatched from 15 to 21 June; the majority having hatched 16 and 17 June.

First stage. Larger larvae, black ; smaller ones, fallow; the colors becoming of a more uniform hue as the larvae increased in size. Very much like $S$. cecropia larvae. Second stage. Larvae yellow, with black tubercles; head black. Third stage. Back, bluish ; sides, yellow. Tubercles on back, orange-red ; tubercles on sides, blue ; head, yellow.

The other crossings resulting from the keeping of various species together in large cages, when $\delta$ and $q$ moths of the same species were not abtained at the same time, are the following: in a hot-house, 22 May, Telea polyphemus $\$$ and Attacus mylitta S of the Bombay race; $T$. polyphemus ? and Attacus pernyi o ; Samia gloveri 9 and $A$. pernyi $\delta$ : in my house at ordinary temperature, 12 and 13 June, Samia ceanothi $q$ and S. cecropia $\delta$; 15 June, $S$. gloveri $q$ and $S$. cecropia $\delta ; 18$ and 19 June, $S$. cecropia $\$$ and $S$. ceanothi $\delta$. In all the above cases, the ova were infertile.

\section{ON AN AQUATIC SPHINX LARVA.}

\section{BY HERMANN AUGUST HAGEN, CAMBRIDGE, MASS.}

The following letter from the Baron von Reizenstein, in New Orleans, La., was sent to me as a scientific communication by Dr.

\section{J. L. LeConte, of Philadelphia :-}

" From larvae and pupae of a sphinx in my possession, there is every reason for believing that $I$ have made a new acquisition to the lepidopterous fauna of Louisiana. 'They belong to the genus Philampelus, but the larvae far exceed in size those of the other known sphingidae, even of the true sphinx Macrosila rustica (Sphinx chionanthi). I found the larvae feeding on the floating Nymphaea, in the very centre of a draining canal in the outskirts of the city. When I discovered them, their whole body, with the exception of the first three segments, was submerged in the water. When they had devoured one patch of the water plants, they swam with great facility to a new one, the first instance I ever experienced of this habit in the larva of a sphinx, or in any caterpillar. As I am familiar with all the other known larvae of the genus Philampelus, and it is not probably that of $P h$. labruscae, a strictly tropical species, which I do not know, so it is very likely an entirely new species.

Of the other species of Philampelus (peculiar only to the new continent) are until now only known and described: Philampelus vitis Linn., Ph. achemon, Ph. satellitia, Ph. fasciatus, and Ph.lycaon Cram. (posticatus Grote), all occurring here, except achemon, a northern species, and whose larvae are all known to me.

There remains then only Philampelus labruscae, which I do not believe is the sphinx in question. Of 25 larvae (now all pupae) in my possession, I preserved one in alcohol, to have an "argumentum ad hominem" for a further occasion, when I will prepare a correct drawing of the insect in all its stages. 

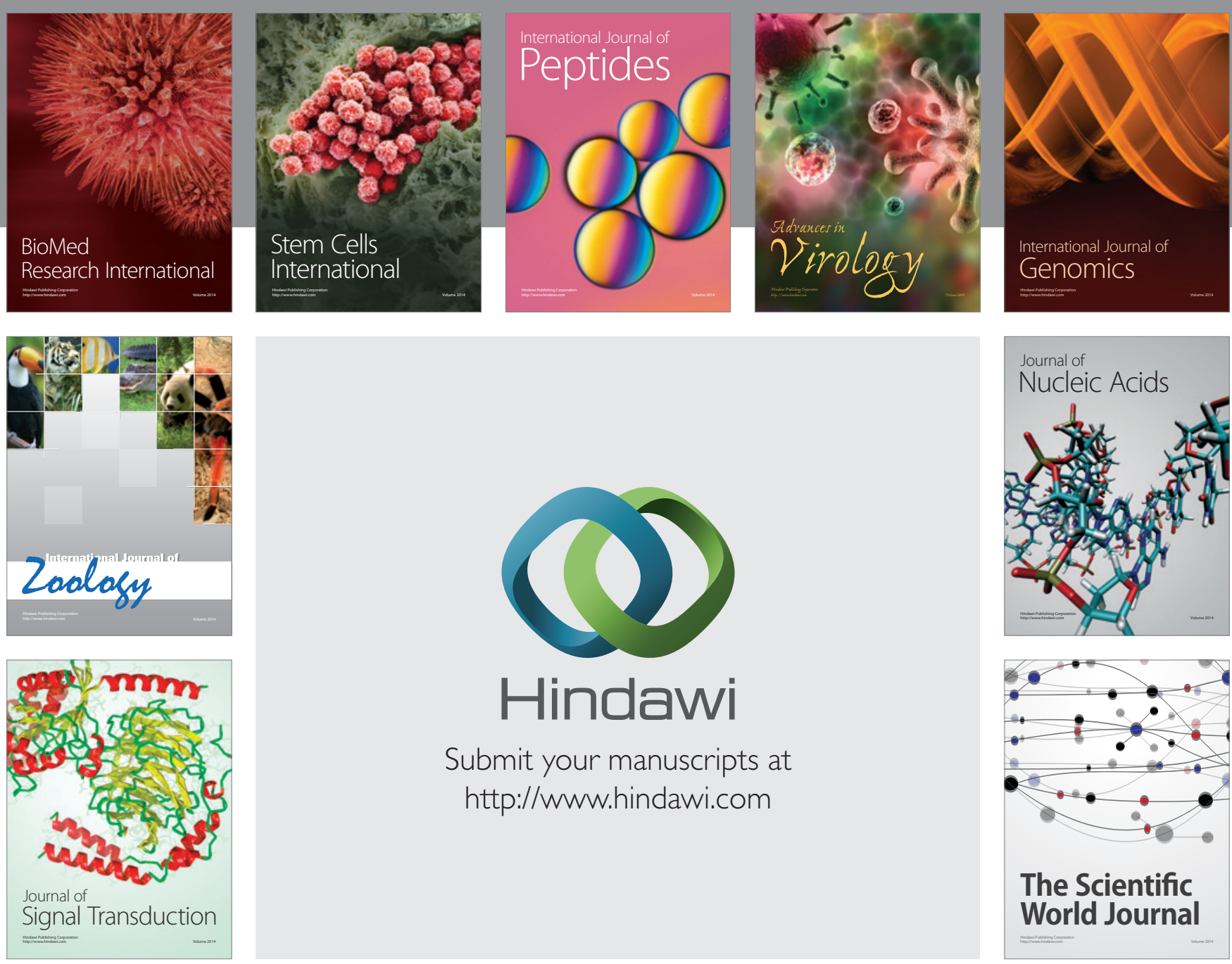

Submit your manuscripts at

http://www.hindawi.com
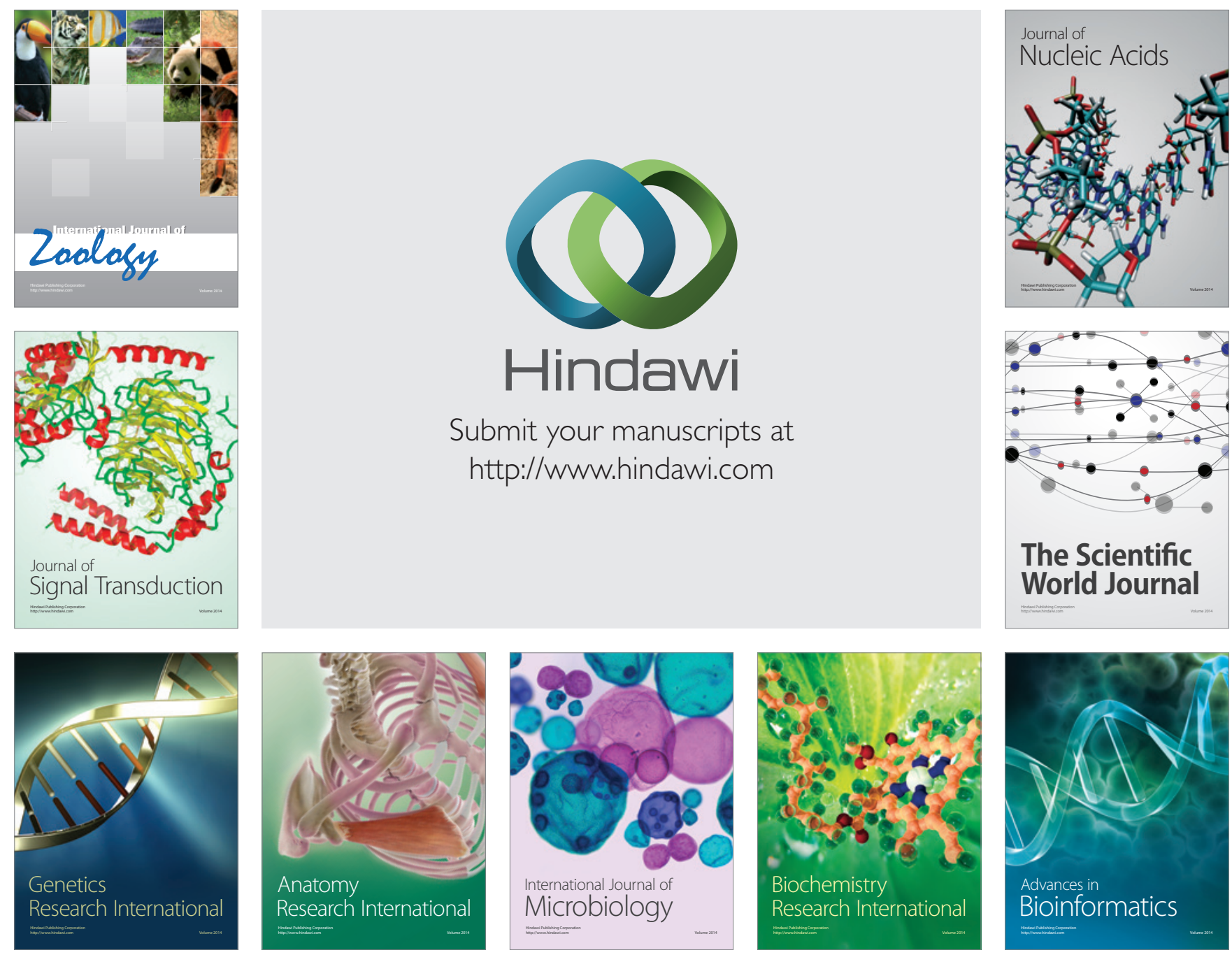

The Scientific World Journal
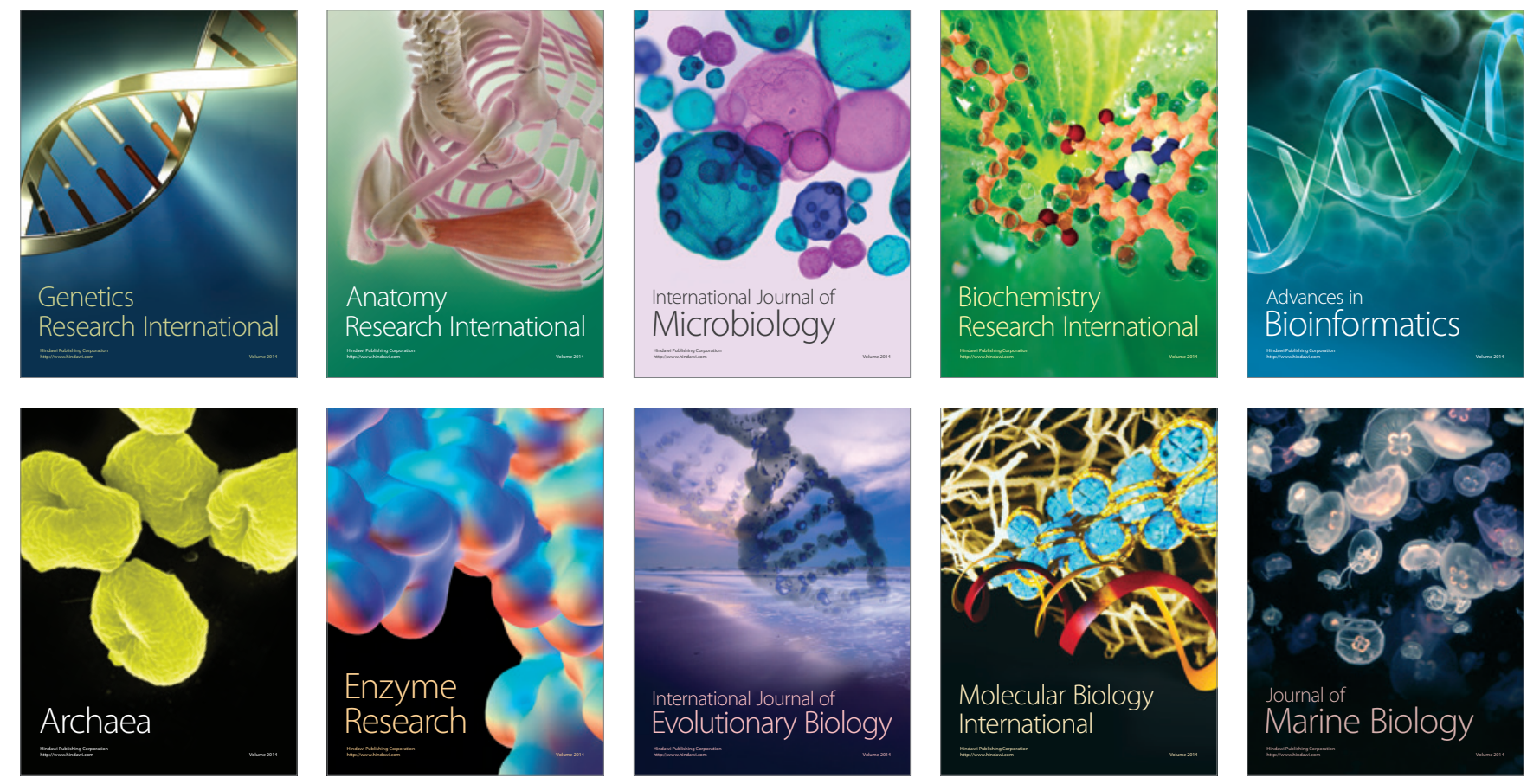